\title{
A 17-yr old boy with productive cough and progressive dyspnoea
}

\author{
J.E. Tulleken*, C.A. van Minnen**, T.J.W. Waterbolk , H.J.M. Groen**, \\ T.S. van der Werf*, J.J.M. Ligtenberg*, J.G. Zijlstra*
}

\section{Case history}

A 17-yr old boy presented with productive cough and progressive shortness of breath. His medical history started four months earlier with successful surgical repair of a longitudinal airway rupture extending from the carina into the left main bronchus following a blunt chest trauma. A follow-up bronchoscopy after one month revealed a narrowing of the left main bronchus by endoluminal granulation tissue formation around the intraluminal nylon stitches. Neodymium/yttrium-aluminium-garnet (Nd/YAG) thermal laser vapourisation with the rigid bronchoscope was attempted twice in three weeks. Although initially successful, the symptoms worsened. The chest radio-

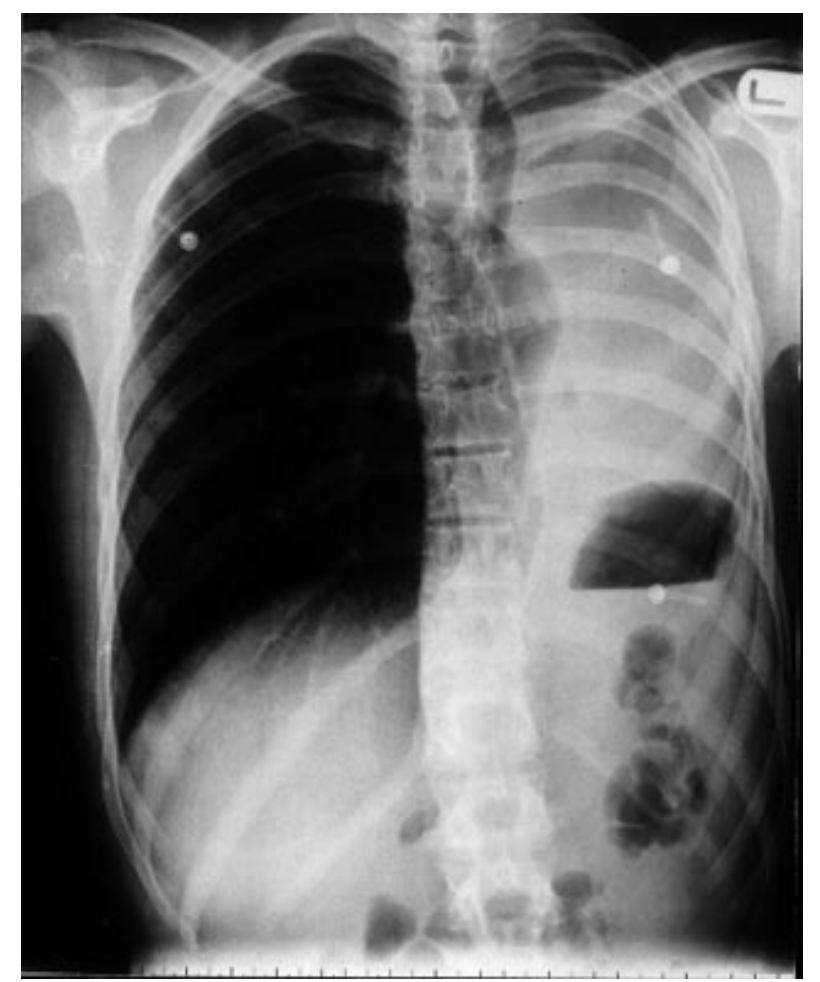

Fig. 1. - Chest radiograph performed on hospital admission in the upright position. graph on hospital admission suggested complete atelectasis of the left lung (fig. 1). On endoscopy purulent secretions were seen while excessive granulation tissue at the site of bronchial repair narrowed the lumen by $>50 \%$. To limit recurrence, stent placement was performed after application of a third Nd/YAG laser treatment. Airway patency was reached. On the distal part of the stent granulation tissue was still present. Following the procedure, oral corticosteroids and nebulized beta-adrenergic agonist therapy were started.

His shortness of breath did not subside and on the day of admission to the intensive care unit (ICU) he had a nonproductive cough and was more dyspnoeic. He was eating and had vomited once. His temperature was $37.3^{\circ} \mathrm{C}$, pulse rate was 110 beats. $\mathrm{min}^{-1}$, respiratory rate was 20 breaths $\cdot \mathrm{min}^{-1}$, and blood pressure was $140 / 80 \mathrm{mmHg}$. Auscultation of his lungs revealed diffuse in- and expiratory rhonchi (left>right). Examination of the heart, abdomen, skin and central nervous system showed no marked abnormalities. Blood analysis showed an elevated leukocyte count of $13.7 \times 109$ L. Biochemical tests were normal. At that time a chest radiograph was performed again (fig. 2).

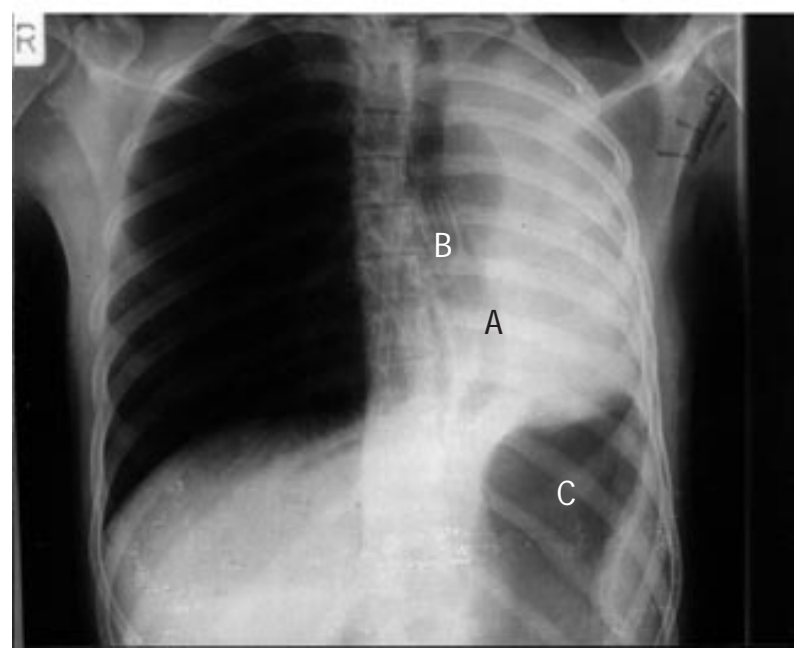

Fig. 2. - Chest radiograph performed 3 days after hospital admission in the bedside, upright position.

\section{BEFORE TURNING THE PAGE, INTERPRET THE RADIOGRAPHS, AND SUGGEST DIAG- NOSIS AND TREATMENT.}

*Dept of Internal Medicine, Intensive \& Respiratory Care Unit (ICB), **Dept of Pulmonary Diseases, and ${ }^{+}$Dept of Cardiothoracic Surgery, Thorax Center, University Hospital Groningen, The Netherlands.

Correspondence: J.E. Tulleken, Intensive \& Respiratory Care Unit (ICB), University Hospital Groningen, P.O. 30.001, 9700 RB Groningen, The Netherlands. Fax: 31503613216 


\section{Interpretation of the chest radiographs}

Figures 1 and 2 suggest complete atelectasis of the left lung. A lateral projection was not made, and the possibility that the atelectasis might be limited to the upper lobe cannot be excluded. Figure 2 shows an endobronchial stent that is positioned in the left main bronchus, a significant amount of gastric air, a mediastinal shift to the left, and no signs of pneumothorax. A dilated airfilled oesophagus can be seen, as illustrated by figure 1 , the effect is more pronounced on figure 2 . The following are identified on interpretation of the radiographs: A: dilated airfilled oesophagus; B: endobronchial stent; $\mathrm{C}$ : gastric air.

\section{Clinical course and treatment}

The chest radiograph showed (fig. 2) a significant amount of gastric air, interpreted as the result of intermittent bag squeezing. Due to progressive respiratory distress and in order to allow a safe bronchoscopy procedure, he was endotracheally intubated and mechanically ventilated. Arterial blood gas analysis with an inspiratory oxygen fraction $\left(F \mathrm{I}, \mathrm{O}_{2}\right)$ of 0.4 showed: $\mathrm{pH}$ : 7.34; oxygen tension in arterial blood $\left(\mathrm{Pa}_{\mathrm{a}} \mathrm{O}_{2}\right): 9.1 \mathrm{kPa}$; carbon dioxide tension in arterial blood $\left(\mathrm{Pa}_{\mathrm{a}} \mathrm{CO}_{2}\right): 6.2 \mathrm{kPa}$; bicarbonate: $24.8 \mathrm{mmol} \cdot \mathrm{L}^{-1}$. A bronchoscopy was performed without accurate visual assessment showing mucus obstruction, some necrotic debris without evidence of stent dislocation. In the following hours gas exchange worsened without evidence of a pneumothorax. No air leak by the nose and mouth was noted. On auscultation air sounds were heard in the epigastrium. Gastric air could not be effectively expelled by nasogastric tube suction. These observations suggested a tracheo-oesophageal fistula. Repeat flexible bronchoscopy was performed which showed a patent stent that ended in the oesophagus.

The patient was operated on with removal of the stent, reconstruction of the oesophagus and bronchus, and left pneumonectomy. The patient made a full and uneventful recovery and two weeks after ICU admission he was discharged from the hospital. Follow-up showed no evidence of an air leak or infection.

Diagnosis: "Broncho-oesophageal fistula secondary to laser therapy and stent placement"

\section{Discussion}

Bronchial rupture in blunt trauma is rare and is caused by compression of the chest with dislocation of the lungs. Surgical repair is the treatment of choice and has been performed successfully $[1,2]$. The prognosis of tracheobronchial ruptures mainly depends on the initial control of respiratory failure and complications. Endobronchial obstruction is frequently encountered after tracheobronchial surgical repair and is usually managed by endoscopic survey and laser therapy [3]. In the case presented here the decision to place an endobronchial stent was based on the fact that airway patency was not restored with $\mathrm{Nd} /$ YAG-laser therapy alone and pneumonectomy was the only, but less attractive alternative. The difficulties in encountering the airway obstruction prompted the endoscopist to place the stent without accurate visual assessment. Over the subsequent days the patient experienced respiratory distress.

Eventually, the clinical diagnosis of broncho-oesophageal fistula was made. The chest radiograph appeared to be the most appropriate initial investigation in the patient. The radiographic findings on admission, already demonstrated a dilated, airfilled oesophagus that suggested the existence of a broncho-oesophageal fistula (fig. 1). Although pneumothorax or free mediastinal and subcutaneous air, would be a much stronger argument in favour of a fistula. Broncho-oesophageal fistula is usually demonstrated by barium swallow or by direct endoscopy. The latter is a highly diagnostic modality but initially it did not confirm the clinical suspicion. Also, in other patients with broncho-oesophageal fistula, bronchoscopy was not entirely reliable [4]. The limited two dimensional picture through the scope sometimes contributes to a delayed identification of the problem $[5,6]$.

The present case illustrates that recognition of clinical and radiographic symptoms and a high index of suspicion is warranted for an early diagnosis and treatment.

Keywords: Broncho-oesophageal fistula, endobronchial stent, neodymium/yttrium-aluminium-garnet-laser.

\section{References}

1. Velly JF, Martigne C, Moreau JM, Dubrez J, Kerdi S, Couraud L. Post traumatic tracheobronchial lesions. A follow-up study of 47 cases. Eur J Cardiothorac Surg 1991; 5: 352-355.

2. Pillgram-Larsen J, Fjeld NB, Gronseth K. Bronchial ruptures are rare and should be surgically treated. Tidsskr Nor Laegeforen 1998; 118: 532-534.

3. Madden BP, Kumar P, Sayer R, Murday A. Successful resection of obstructing airway granulation tissue following lung transplantation using endobronchial laser (Nd:YAG) therapy. Eur $J$ Cardiothorac Surg 1997; 12: 480-485.

4. Kelly JP, Webb WR, Moulder PV, Monstouakas NM, Lirtzman M. Management of airway trauma. II. Combined injuries of the trachea and esophagus. Ann Thorac Surg 1987; 43: 160-163.

5. Unger M. Tracheobronchial stents, stunts, and medical ethics revisited. Chest 1996; 110: 1133-1135.

6. Weber SM, Schurr MJ, Pellett JR. Delayed presentation of a tracheoesophageal fistula after blunt chest trauma. Ann Thorac Surg 1996; 62: 1850-1852. 